\section{OPEN ACCESS}

Edited by:

Peter Christian Petersen,

Langone Medical Center, New York

University, United States

Reviewed by:

Jessica Ausborn,

College of Medicine, Drexel University,

United States

Rune W Berg,

University of Copenhagen, Denmark

${ }^{*}$ Correspondence:

Petra Mocellin

Petra.Mocellin@lin-magdeburg.de

Sanja Mikulovic

Sanja.Mikulovic@lin-magdeburg.de

Received: 24 April 2021

Accepted: 28 June 2021

Published: 22 July 2021

Citation:

Mocellin P and Mikulovic S (2021)

The Role of the Medial

Septum-Associated Networks

in Controlling Locomotion

and Motivation to Move.

Front. Neural Circuits 15:699798.

doi: 10.3389/fncir.2021.699798
The Role of the Medial Septum-Associated Networks in Controlling Locomotion and Motivation to Move

\author{
Petra Mocellin ${ }^{1,2 *}$ and Sanja Mikulovic ${ }^{3 *}$ \\ ${ }^{1}$ Department of Cellular Neuroscience, Leibniz Institute for Neurobiology, Magdeburg, Germany, ${ }^{2}$ International Max Planck \\ Research School for Brain and Behavior, Bonn, Germany, ${ }^{3}$ Research Group Cognition and Emotion, Leibniz Institute \\ for Neurobiology, Magdeburg, Germany
}

The Medial Septum and diagonal Band of Broca (MSDB) was initially studied for its role in locomotion. However, the last several decades were focussed on its intriguing function in theta rhythm generation. Early studies relied on electrical stimulation, lesions and pharmacological manipulation, and reported an inconclusive picture regarding the role of the MSDB circuits. Recent studies using more specific methodologies have started to elucidate the differential role of the MSDB's specific cell populations in controlling both theta rhythm and behaviour. In particular, a novel theory is emerging showing that different MSDB's cell populations project to different brain regions and control distinct aspects of behaviour. While the majority of these behaviours involve movement, increasing evidence suggests that MSDB-related networks govern the motivational aspect of actions, rather than locomotion per se. Here, we review the literature that links MSDB, theta activity, and locomotion and propose open questions, future directions, and methods that could be employed to elucidate the diverse roles of the MSDB-associated networks.

Keywords: MSDB, locomotion, motivation, theta, cell types

\section{INTRODUCTION}

Movement, and above all locomotion, is essential for most species' survival: we move to reach a specific place, receive a reward, flee from a predator or attack prey. However, while extensive research has been conducted on brain circuits underlying locomotion (Sinnamon et al., 1987; Fuhrmann et al., 2015; Howe and Dombeck, 2016; Capelli et al., 2017; Justus et al., 2017; Caggiano et al., 2018), surprisingly less attention has been paid to the influence that the internal state of a subject may have on specific motor performances (Mogenson et al., 1980; Ferreira-Pinto et al., 2018). For example, the intensity at which a movement is performed may arise from a cumulative integration of individual sensory modalities (Bland and Oddie, 2001) or it may be based on experience and thus be retrieved from memory. Likewise, the decision to act or not is shaped by both the external and the internal environment, a combination of external inputs, intrinsic drive, and visceral homeostasis. This implies that similar motor outputs could result from different motivations and intentions guided by different brain regions and/or circuits. 
The brain networks underlying the execution and planning of locomotion are widely spread throughout the central nervous system: spinal cord, hindbrain, midbrain, basal ganglia, and cortex (Garcia-Rill, 1986; Jordan et al., 2008; Okada and Okaichi, 2010; Kiehn, 2016). Certain structures are proven to be essential for locomotion, for example the central pattern generator in the spinal cord (Sherrington, 1910; Brown, 1914) or the mesencephalic locomotor region in the brainstem (Douglas et al., 1993), as their lesions lead to severe impairment in movement or even immobility. Other regions are actively involved prior and during locomotion: the motor cortex performs motor planning ( $\mathrm{Li}$ et al., 2015), the striatum facilitates voluntary movement execution (Tang et al., 2007; Cui et al., 2013), and the cerebellum adjusts the action based on the environmental changes (Robinson, 1995). Despite the significant amount of work already conducted to understand the neural basis of movement and how the signal is transmitted from the neurons in the central nervous system to the muscles, we still do not understand "where" the decision to start moving is formed in the brain. Seminal studies performed in the 70 s demonstrated that electrical stimulation of a great variety of brain regions can ultimately lead to movement: the Medial Septum and diagonal Band of Broca (MSDB), the basal forebrain bundle, the hypothalamic nuclei and the ventral tegmental area (VTA) are among the most studied circuits (Mogenson et al., 1979, 1980; Parker and Sinnamon, 1983; Sinnamon et al., 1984, 1987; Lee et al., 1988; Decker et al., 1995). However, as previously mentioned, an animal can move for different reasons and we know that the activity of different areas drives specific motivation to move. The preoptic area is involved in movement linked to parental, sexual, and maternal behaviour (Noonan and Kristal, 1979; Gorski, 1984; Hull and Dominguez, 2007; Kuroda and Numan, 2014), the lateral septum (LS) mediates rage and attack towards conspecifics (Wong et al., 2016), the hypothalamus plays a role in food seeking behaviour (Qualls-Creekmore et al., 2017) and the MSDB is mostly linked to navigation (Brandon et al., 2011; Koenig et al., 2011; Wang et al., 2015), but also other movement-related behaviours including exploration, anxiogenic and anxiolytic locomotion (Figure 1). While the advances in techniques and methods to manipulate and study neurons have tremendously developed in the last two decades, the unsupervised sub-second analysis of the behavioural readout has just recently started to attract the neuroscience field's attention (Hausmann et al., 2021).

The MSDB is one of the most interconnected regions of the brain given its key position in the middle of the basal forebrain. Among others, it receives inputs from thalamus, supramammillary nuclei (SUM), VTA, nucleus incertus (NI), and cerebellum (Ang et al., 2017; Müller and Remy, 2018; Watson et al., 2019), and projects back to both dorsal and ventral hippocampus (HPC), cingulate and insular cortex, hypothalamus, habenula, and VTA (Swanson and Cowan, 1979; Fuhrmann et al., 2015; Ang et al., 2017). The MSDB has been considered a central subcortical hub for information processing, and it has been intensively studied for its high number of cholinergic neurons. In fact, for several years, MSDB was thought to comprise only two different kinds of cells: the cholinergic ones, positive for the choline acetyltransferase (ChAT) enzyme, and the inhibitory interneurons. Only at the beginning of the 21st century, a third subpopulation was described: the glutamatergic neurons that express transcripts for the vesicular glutamate transporter 2 (VGluT2; Sotty et al., 2003) and do not overlap with the cholinergic nor the GABAergic populations. MSDB has been implicated in numerous behaviours related to movement including cognitive tasks (Colom et al., 2005; Mamad et al., 2015; Wang et al., 2015; Jacob et al., 2017), locomotor (Bland and Oddie, 2001; Bland et al., 2007; Fuhrmann et al., 2015; Justus et al., 2017; Jin et al., 2019), and emotional responses (Highfield et al., 2000; Khakpai et al., 2013; Knox and Keller, 2016; Jiang et al., 2018). It has also been historically related to theta rhythm $(4-12 \mathrm{~Hz})$, a distinctive oscillatory activity that can be either recorded in the HPC of anesthetised and immobile animals (so called type 2 theta), or during locomotor behaviour (so called type 1 theta) (Kramis et al., 1975). Interestingly, lesions or pharmacological silencing of MSDB abolish theta oscillations in the HPC (Lee et al., 1994). A large body of studies in awake animals proved a link between theta activity and locomotion and revealed that MSDB silencing not only impacts the hippocampal theta rhythm, but also reduces the overall locomotor activity (Lee et al., 1988; Decker et al., 1995; Fraser et al., 1991). However, the development of more sophisticated approaches like chemo- and optogenetic manipulations reported little effect on locomotion following MSDB inhibition (Sweeney et al., 2017). These conflicting results can be partially explained by the indistinct and generalised silencing of a brain area in pharmacological or lesion studies, versus the more accurate and precise inhibition achieved with modern techniques. Indeed, optogenetic experiments carried in rodent Cre lines and targeting specific MSDB's subpopulations (Fuhrmann et al., 2015; Zhang et al., 2018) have shown that the observed locomotor output depends on the activation of the septal glutamatergic neurons. We here review the literature that links MSDB, theta activity, and locomotion, with a focus on the overlooked fact that an animal moves for different reasons and with different motivations. We list open questions and future directions, as well as methods that could be employed to elucidate the diverse behavioural roles of the MSDB-related networks.

\section{EARLY BEHAVIOURAL STUDIES WITH SEPTAL ELECTRICAL STIMULATION OR ELECTROLYTIC LESIONS}

For decades, electrical stimulation or lesions of the septal area were the only ways experimenters possessed to understand the physiological role of this basal forebrain region. Electrical stimulation of the septal area showed, from the very beginning, a broad range of effects: in awake animals it produced positive reinforcement (Olds and Milner, 1954), no reduction of food intake (Mabry and Peeler, 1968), but reduction of saline preference (Gentil et al., 1971) and of water intake (Wishart and Mogenson, 1970). An increase in shaking, grooming and feeding was observed after stimulation 


\title{
Anxiety/Fear Response
}

LHb (Zhang et al., 2018)

LH (Barbano et al., 2020)

BLA (Tye et al., 2011)

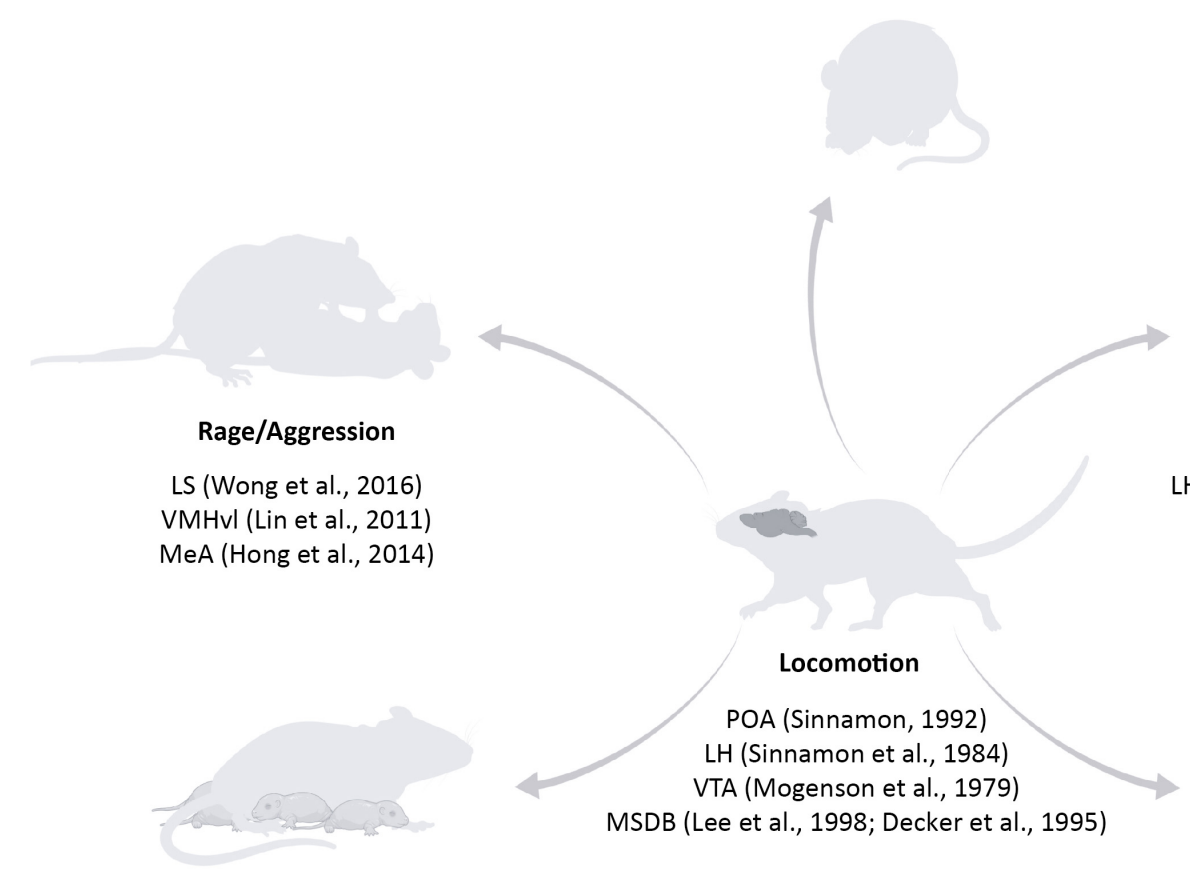

Sexual/Parental Behaviour

Exploration/Novelty

MPOA (Kuroda et al., 2014; Hull et al., 2007)

BNST (Klampfl et al., 2016)

\author{
LPO (Subramanian et al., 2018) \\ NAc (Hooks et al., 1995) \\ IPN (Molas et al., 2017)
}

FIGURE 1 | Subcortical structures involved in locomotion and in different motivations to move. Key areas in the basal forebrain, hypothalamic, and midbrain structures have been classically linked to locomotion (for example, POA, LH, VTA, and MSDB) (Mogenson et al., 1979; Sinnamon et al., 1984; Lee et al., 1988; Sinnamon, 1992; Decker et al., 1995). With the rise of new tools, it was possible to specify the contribution of specific areas on distinct reasons to move: fear responses are controlled by BLA, LHb, and LH (Tye et al., 2011; Zhang et al., 2018; Barbano et al., 2020); food seeking centres have been found in the LH and ARC (Krashes et al., 2011; Qualls-Creekmore and Münzberg, 2018); exploration and novelty are mediated by LPO, NAc, and IPN (Hooks and Kalivas, 1995; Molas et al., 2017; Subramanian et al., 2018); sexual and parental behaviour are mostly related to POA and BNST (Hull and Dominguez, 2007; Kuroda and Numan, 2014; Klampfl et al., 2016); rage and aggression nuclei include LS, VMHvl, and MeA (Lin et al., 2011; Hong et al., 2014; Wong et al., 2016). POA, Preoptic Area; LH, Lateral Hypothalamus; VTA, Ventral Tegmental Area; MSDB, Medial Septum and Diagonal Band of Broca; BLA, Basolateral Amygdala; LHb, Lateral Habenula; ARC, Arcuate Nucleus; LPO, Lateral Preoptic Area; NAc, Nucleus Accumbens; IPN, Interpeduncolar Nucleus; BNST, Bed Nucleus of the Stria Terminalis; LS, Lateral Septum; VMHvl, Ventromedial Nucleus of the Hypothalamus; MeA, Medial Amygdala. Source icons were used from @biorender.com.

(Altman and Wishart, 1971), as well as an increase in selfstimulation (Gordon and Johnson, 1981; Cazala et al., 1988), hyperactivity, and yawning (Wishart et al., 1973). However, when applying electrical stimulation, it is cumbersome to define the volume of the affected area and it remains unknown which brain regions are sending the input or receiving the electrical output. Furthermore, it remains unclear whether the targeted area is necessary or just involved in the observed behavioural process (Vaidya et al., 2019). For these reasons, using lesions that permanently destroy the area of interest may offer more relevant information in relation to the studied behaviour than the electrical activation of the circuit.

The first seminal work describing the behavioural effects following septal lesions dates back to 1953 (Brady and Nauta,
1953). Building on few previous studies performed in cats (Spiegel et al., 1940), this rodent based study hypothesised a role for the septum in emotional and affective behaviour. Animals with septal lesions showed increased rage and startle responses when handled by the experimenter or presented with auditory stimuli (Caplan, 1973). Even innocuous stimuli leading to exploration in non-lesioned animals were eliciting freezing or attacks in the lesioned ones. However, while apparently any stimulus would lead to exaggerated responses, it was reported that the same animals were less anxious and fearful than the controls when placed back in the chambers where they were conditioned with a foot shock prior to the surgery (Caplan, 1973). These seemingly contradictory results showing both hyperreactivity and anxiolytic effects after septal lesions promoted a series of other 
studies trying to elucidate the role of the septal area and the contribution of its subregions to these behavioural paradigms. In the meantime, an increasing amount of data accumulated and raised the idea of the so called "septal syndrome", septal hyperreactivity or septal hyperemotionality not only in mice and rats, but also in hamsters, cats, and monkeys (Brady and Nauta, 1955; King, 1958; Votaw, 1960; Lubar, 1964; McCleary et al., 1965; Buddington et al., 1967; Sodetz et al., 1967). The core results appointed the septal circuits as inhibitory networks suppressing responses to stimuli with a predominant role in negatively reinforced behaviours. Thus, septal lesions disinhibit and enhance the animal responsivity to negative events, while also leading to a lack of response suppression in avoidance tasks (Caplan, 1973). It is, however, important to note that the results obtained in the abovementioned experiments resulted from a general lesion of the basal forebrain with no specificity for the MSDB or LS, and included also the bed nucleus of the stria terminalis. When lesions were targeted to the MSDB only, it became evident that the major role in the septal syndrome was played by the LS, with a minor contribution of the MSDB in enhancing the aggressive behaviour and the animal's emotionality (Poplawsky and Johnson, 1973; Albert and Richmond, 1975; Albert and Chew, 1980; Lee et al., 1988). These data were confirmed in a more recent study showing that LS GABAergic projections to the ventromedial hypothalamus are necessary to suppress male aggression in mice. When the same projections are inhibited, the number of attacks to both males and females increased and a "septal rage" behaviour was reported (Wong et al., 2016).

A different picture arose when focussing on lesions of the MSDB specifically: MSDB disruption resulted in submissive behaviour with conspecifics (Poplawsky and Johnson, 1973), decreased horizontal and vertical movements when measuring exploratory and locomotor behaviour (Lee et al., 1988) slower rate of habituation (Decker et al., 1992), deficits in spatial tasks (Fraser et al., 1991), decreased spatial discrimination and increased time in the open arm of the elevated plus maze (Decker et al., 1995). If some of these effects (deficits in exploration, locomotion, and habituation) were expected in light of the strong projections of the MSDB to the HPC formation and their involvement in navigation and memory (Pang et al., 2011; Mamad et al., 2015; Hinman et al., 2018); other results like the submissive behaviour and the anxiolytic effect are less easy to interpret. Moreover, several studies report impaired exploratory and locomotor skills of MSDB-lesioned animals only in the first post-operative trial, showing a slower but constant increase in performances over days until the point of being not significantly different from controls (for example in Myhrer, 1989). Possible explanations behind these phenomena can be identified in increased anxiety of MSDB-lesioned animals when exposed to novel environments (neophobia), deficits in sensory information processing and/or in short- and long-term memory (thus inability to recognise a novel environment and explore it), fastest stimulus satiation or increased inertia. Overall, early investigations of the MSDB highlighted a very close relationship between this brain area and locomotion. Nevertheless, it remained unclear what was the exact contribution of the MSDB in driving and/or modulating movement-related responses. Relevant to the interpretation of these findings is the fact that all reported studies were performed in rats and not in mice. Compared to mice, rats are predator and not prays, they show more prominent social interactions and more advanced cognitive processing allowing them to solve complex tasks (Scott, 1966). They also differ in terms of genetic background, gene expression, and ion channels, making it cumbersome to compare the behavioural effects of MSDB manipulation between the two species (Bonthuis et al., 2010; Hok et al., 2016). In addition, these studies used electrolytic lesions of the septal area, meaning that not only the somata, but also the axonal fibres crossing the region, were affected. Moreover, permanent lesions of a brain area may lead to reorganisation of the system and changes in the homeostatic activity of the network, thus the timing (immediate vs weeks or months after the lesions) at which the studies were conducted are relevant to properly interpret the lesions' effect on the underlying behavioural output.

\section{PHARMACOLOGICAL MANIPULATION OF THE MSDB}

From the beginning of the 80s pharmacology emerged as a new tool to silence specific brain areas. Agonists and antagonists of ion channels and receptors became a widely used means to investigate the effects of blocking specific neurotransmitters and allowed the silencing of areas with only small effects on the en passant fibre tracts. Indeed, muscimol infusion only blocks cell bodies, while local anaesthetics and tetrodotoxin can also block the passing fibres (Martin and Ghez, 1999). The latter can affect projecting axons originating from cortical and forebrain structures. Those projections take part in the information flow from the MSDB through three different pathways: to the hippocampus via the dorsal fornix fimbria; to the habenular nuclei through the stria medullaris; and via the medial forebrain bundle running ventral into the thalamic and hypothalamic regions, crossing the midbrain and reaching the brainstem (Meibach and Siegel, 1977).

Muscimol (GABA A agonist) and lidocaine $\left(\mathrm{Na}^{+}\right.$channels blocker) were used to temporarily silence or reduce the activity in the targeted brain region through two opposite mechanisms: increasing inhibitory interneuron activity through disinhibition and reducing action potential firing probability, respectively. When applied in the MSDB, the most striking effect on the animal's behaviour was the impairment in tasks requiring memory and navigation (Chrobak et al., 1989; Nagahara and McGaugh, 1992; Walsh et al., 1998), confirming the crucial importance of septal projections to the HPC formation. MSDB inhibition via lidocaine seemed not to affect the running speed (Koenig et al., 2011), but to reduce anxiety and increase open arm exploration in a plus maze (Lamprea et al., 2010). Muscimol infusions resulted in more diversified and sometimes contradictory behaviours. Upon muscimol infusion, mice displayed both increased arousal and locomotor activity (Osborne, 1994), or slightly decreased running speed (Wang et al., 2015) or even no effect on locomotion (Brandon et al., 2011) 
depending on the experimental conditions. Indeed, muscimol leads to the specific excitation of GABAergic neurons in the MSDB; this, in turn, could lead to the activation of different pathways related to either arousal (Wu et al., 2002), nociception (Ang et al., 2015), anxiety (Vickstrom et al., 2020), or rewardseeking behaviour, as demonstrated by an increase of lever presses for muscimol self-administration (Gavello-Baudy et al., 2008). Thus, it is not surprising that the use of this drug leads to a diverse repertoire of behavioural outcomes.

Alongside muscimol and lidocaine, a wide variety of other manipulation approaches have also been studied in relation to MSDB and locomotion. For example, infusion of histamine or pyrilamine increased locomotion (Zarrindast et al., 2006), depletion of the relaxin-family peptide-3 receptor (RXFP3) impaired spatial strategy search (Haidar et al., 2019), the neurokinin 1 receptor (NK1R) facilitated exploratory behaviour (Ng et al., 2020), while CaV3.1 (T-type voltage gated calcium channel) knock down increased exploration of an object (Jung et al., 2019). Moreover, MK 801 and ketamine lead to hyperlocomotion (Ma and Leung, 2007), while a somatostatinsensitive mechanism facilitated inactivity periods in open field (Ng et al., 2020). A recent study applied the cooling of MSDB as an alternative and complementary tool to pharmacology in order to investigate the overall effect of the MSDB circuit inhibition. The authors showed a reduction of theta rhythm upon cooling as well as an increase in number of choice errors in a spatial navigation task (Petersen and Buzsáki, 2020). While these results are valuable to investigate the general aspects of MSDB circuit function and neuromodulation, the specific contribution of the distinct cell types within the MSDB was not investigated until the development of Cre-dependent manipulation in transgenic mouse lines.

\section{CELL TYPE SPECIFIC MANIPULATIONS OF THE MSDB}

The first studies using Cre lines focussed on the impact of cholinergic (ACh) and GABAergic septal neurons on animal behaviour.

Choline acetyltransferase (ChAT)-Cre transgenic mice have been considered the gold standard for ACh neurons targeting. Chemogenetic silencing of these neurons in the MSDB alleviates pain induced anxiety (Jiang et al., 2018) and produces a general anxiolytic effect corroborated by an increase in distance travelled in the open field test and higher open arms entrances in the elevated plus maze test (Zhang et al., 2017). Thus, ACh MSDB transmission seems to promote anxiety possibly through its projections to the ventral HPC and the prefrontal cortex (Adhikari et al., 2010; Mikulovic et al., 2018). This finding could partially reconcile the reduced locomotor activity and anxiety-like behaviour described by some early lesions studies (Caplan, 1973), while reproducing the increased time in the open arm and exploratory behaviour shown in others (Decker et al., 1992). We could speculate that non-specific lesions could differentially affect ACh transmission and projections outside the MSDB, thus eliciting opposite kinds of behaviours. Chemogenetic activation of ChAT positive cells in MSDB reduces frequency of theta oscillations in the entorhinal cortex and gives rise to the sense of novelty and anxiety by increasing the time of immobility and avoidance of the centre (Carpenter et al., 2017). In line with these observations, several studies (Adhikari et al., 2010, 2011; Mikulovic et al., 2018) have shown that anxietyrelated behaviour induces slower theta rhythm, resembling the cholinergic-dependent type 2 theta, particularly in the ventral HPC. Interestingly, depending on the context, type 2 theta may underlie anxiogenic or anxiolytic behaviour. For example, in open field or elevated plus maze anxiety-related tests (Adhikari et al., 2010, 2011) cholinergic-dependent type 2 theta relates to the increased anxiety and reduction in locomotion. Differentially, in a predator odour test (Mikulovic et al., 2018), type 2 theta underlies increased risk-taking behaviour and locomotion. These results indicate that the behavioural effect of the type 2 theta might depend on the arousal level, commonly related to the acetylcholine levels (Pepeu and Giovannini, 2004).

GABAergic neurons comprise a wide variety of cell types expressing different proteins such as parvalbumin (PV), somatostatin (SST), or calretinin. Specific modulation of GABAergic neurons through Gad65-Cre, Gad67-Cre, PV-Cre, or SST-Cre lines elucidated the role of interneurons in the MSDB network showing how different projection targets give rise to different behaviours. GABAergic MSDB neurons densely project to the HPC formation and are strictly linked to theta generation not only during movement, but also during rest and sleep. Manipulation of the GABAergic septal-hippocampal network has an impact on memory discrimination (Salib et al., 2019) and sequential learning (Dwyer et al., 2007) most probably due to the disruption of internally generated theta oscillations. Activation of these neurons during rapid-eye-movement (REM) phases also affects spatial and contextual memory consolidation in mice (Boyce et al., 2016). On the other hand, activation of MSDB interneurons was reported to increase object exploration in awake animals and type 2 theta rhythm in anaesthetised animals, without affecting open field exploration (Gangadharan et al., 2016). $\mathrm{PV}^{+}$cells in the MSDB overlap with the population of the hyperpolarization-activated cyclic nucleotide-gated (HCN) channel expressing neurons and present pacemaker activity responsible for theta entrainment in the MSDB (Varga et al., 2008). SST neurons instead comprise a small population of basal forebrain neurons, which in the MSDB appear to be responsible for spatial working memory. When photo-inhibited, they do not affect the animal speed but instead disrupt the alternation index in a Y maze test (Espinosa et al., 2019). Finally, little is known about MSDB interneurons' input and output connectivity outside the MSDB and HPC formation, but it has been shown that GABAergic transmission to the $\mathrm{MHb}$ is sufficient to entrain the local circuit firing (Choi et al., 2016) and seems to mediate an anxiogenic and depressive state of the animal modulated by the endocannabinoid signalling (Vickstrom et al., 2020).

Glutamatergic $\left(\mathrm{VGluT2}^{+}\right)$neurons were only recently described as part of the MSDB circuit. They are mostly located in the septum midline and in the diagonal band of Broca, and they are highly interconnected (Manseau et al., 2005). While the majority of the early studies (Manns et al., 2001; 
Hajszan et al., 2004; Colom et al., 2005) had focussed on their electrophysiological and molecular characteristics, several recent studies tried to elucidate the involvement of this cell type in behaviour. Optogenetic stimulation of these neurons leads to entraining of theta oscillations in the HPC (Robinson et al., 2016), locomotor activity (Fuhrmann et al., 2015), and appetite suppression (Sweeney et al., 2017). In particular, this is the only cell type in MSDB whose activation leads to nearly instantaneous locomotion that lasts for several seconds following the stimulus offset (Fuhrmann et al., 2015). It has been recently shown (Korvasová et al., 2021) that the locomotor effect that ensues upon MSDB VGluT2 ${ }^{+}$cell stimulation does not require theta oscillations, nor relies upon local MSDB connectivity, given that locomotion effect persists even when the synaptic connectivity in MSDB is completely blocked. Furthermore, the persistent locomotion is linked to intrinsically generated persistent firing of the MSDB VGluT2 ${ }^{+}$neurons.

Tracing studies (Fuhrmann et al., 2015; Agostinelli et al., 2017; Zhang et al., 2018) have shown that MSDB VGluT2 ${ }^{+}$ neurons project to different brain areas: the HPC, the $\mathrm{LHb}$, POA, the paraventricular (PVH), lateral $(\mathrm{LH})$, and posterior $(\mathrm{PH})$ hypothalamic nuclei, the SUM, the VTA, the NI, and the raphe nucleus. Interestingly, manipulation of glutamatergic projections in each of these target areas exerted a different effect. In the LHb it caused place aversion without affecting the locomotor activity (Zhang et al., 2018) that seemed to be mediated by POA projections (Zhang et al., 2018). MSDB inputs to LH have been involved in arousal: their optogenetic activation promotes wakefulness and theta power, while their silencing increased NREM sleep (Manseau et al., 2005). This network seems to be also related to reinforcement and motivation through MSDB inputs to the VTA. When self-stimulating these projections, the animals will increase lever pressing and this action in turn increases nucleus accumbens (NAc) DA release (Kesner et al., 2020), classically associated to rewarding mechanisms.

Overall, it seems clear that MSDB cell types and their faceted projections exert a quite broad effect on animal behaviour. ChAT neurons are strongly projecting to the vHPC and are involved in anxiogenic and anxiolytic responses. They may play a role in guiding an animal's action based on its internal state, thus modifying locomotor responses based on possible threatening stimuli present in the environment (Mikulovic et al., 2018). GABAergic septal interneurons, on the other side, are highly interconnected inside the MSDB and with the HPC formation (Freund and Antal, 1988; Gonzalez-Sulser et al., 2014; Salib et al., 2019; Schlesiger et al., 2021), for this reason they play a major role in pace making activity and theta generation. To our knowledge, they do not send dense projections to other cortical or subcortical regions apart from the HPC formation and some related structures like the retrosplenial cortex (Unal et al., 2015) and their role in behaviour has not been deeply investigated so far. These interneurons appear to be active in aversive conditions as for example nociception, anxiety and depressive states, or in promoting arousal, that can be linked to an increase in alert and awareness for the animal to be ready to react. Finally, VGluT2 ${ }^{+}$neurons are the group of MSDB cells more strongly related to movement. Their optogenetic activation induces locomotion and reinforcement effects. Depending on their output region they may mediate place aversion (as for example when activating the LHb), purely locomotion (as for POA projections) or wakefulness (through their inputs to $\mathrm{LH}$ ). Their role in behaviour is still under investigation but the data collected so far allow speculating for a key involvement of these neurons in action initiation. The fact that their stimulation on the somata or on the projections increase the overall arousal of the animals and leads them to move, shows the VGluT2 ${ }^{+}$MSDB neurons as possible candidates to mediate "fast" responses to the context the animal is in, as opposed to the LS mediated responses that appear to require more time as they must integrate more diversified inputs (Wirtshafter and Wilson, 2021).

How these three cell populations interact, and how their cross-talk can influence an animals' behaviour is still an open question. However, several studies have focussed on their interplay associated with the generation and modulation of theta rhythm, locally and in target structures of the MSDB.

\section{MSDB, THETA ACTIVITY, AND LOCOMOTION PLANNING}

While initially studied in relation to locomotion, MSDB has been in the last five decades mostly investigated in relation to theta oscillations in the HPC, as MSDB lesions or pharmacological inactivation abolished theta rhythm (Petsche and Stumpf, 1960; Petsche et al., 1962; Donovick, 1968; Gray, 1971; Kramis et al., 1975; Andersen et al., 1979; Buzsáki et al., 1986; Kocsis et al., 1999; Brandon et al., 2011; Koenig et al., 2011; Müller and Remy, 2018; Zutshi et al., 2018). However, a long-standing question is how these functions are associated and act together in the generation of behavior. Early studies (Yoshii et al., 1966; Vanderwolf, 1968) have shown that theta oscillations can be recorded in the HPC during voluntary motor behaviour such as walking, running, jumping, rearing, swimming, and digging, the so called type 1 behaviours (Pickenhain and Klingberg, 1967; Vanderwolf, 1968; Whishaw and Schallert, 1977). In contrast, during motor behaviours such as chewing, licking, grooming, and shivering, theta rhythm is absent and a large-amplitude irregular field activity (LIA) is recorded in the HPC. These behaviours are called type 2 or automatic behaviours (Vanderwolf, 1968; Sainsbury, 1970). Theta frequency was reported to increase as a function of speed (Bland and Vanderwolf, 1972; Hinman et al., 2011, 2016; Gupta et al., 2012; Winter et al., 2015), while more recent observation in rats reported mostly correlation with acceleration (Kropff et al., 2021). Theta amplitude correlates with the vigour (e.g., theta amplitude during a run or jump is higher than during a walk) (Whishaw and Vanderwolf, 1973). Significant body of evidence suggests that different types of theta rhythms in the HPC, driven by different MSDB inputs (cholinergic, GABAergic or glutamatergic), accompany different types of movementrelated behaviours. The so-called type 1 theta, characterised by a higher oscillatory frequency $(8-12 \mathrm{~Hz})$, accompanies type 1 behaviours and it is controlled by the glutamatergic MSDB neurons (Fuhrmann et al., 2015). MSDB VGluT2 ${ }^{+}$ neurons fire mostly tonically during theta oscillations and their 
optogenetic stimulation drives theta activity and locomotion speed in a frequency dependent manner (Fuhrmann et al., 2015). Differently, a small subset of MSDB GABAergic neurons expressing PV display highly rhythmical discharge, phase locked to the ongoing theta oscillations (Kocsis et al., 2021) and their optogenetic activation controls the oscillatory frequency outside the endogenous theta range and does not affect locomotion (Zutshi et al., 2018). Those neurons are thus commonly referred to be the pacemakers of theta activity (Zutshi et al., 2018; Kocsis et al., 2021). The less explored type of theta oscillations is type 2 theta, proven to be dependent on the cholinergic MSDB system. This rhythm has been mostly observed in immobile animals that are in a sensory processing mode (Kramis et al., 1975; Kramis and Routtenberg, 1977; Bland et al., 1984). Several stimuli were reported to induce type 2 theta, including olfactory, visual, auditory, and tactile stimulation. Type 2 theta appearance habituates following the repeated representation of the stimulus (Sainsbury and Montoya, 1984) and it has been proposed to code for the movement that follows. Brian Bland, one of the pioneers on the studies of type 2 theta activity, has put forward the theoretical framework that this rhythm plays a major role in "sensorimotor integration" (Bland et al., 1984; Bland, 1986). This hypothesis is centred around the idea that the circuitry underlying theta rhythmogenesis continuously provides the updated information about the changing environmental conditions to the voluntary motor system. In other words, animals are permanently exposed to a number of sensory stimuli in the environment of which some are relevant for the survival, while others can be ignored. This implies that neural systems that process the sensory information must recruit appropriate motor responses in order to make the appropriate final decision.

One study (Oddie et al., 1997) has tested this hypothesis in a very interesting way. In their paradigm, Oddie et al. (1997) investigated a pair of hungry rats fighting for a piece of food. The eating rat was called "victim," while the rat attempting to steal the food was named "robber." Robber's action was regarded as the eliciting stimulus, while dodging - the lateral evasive movement by the victim rat, was the measured behavioural response. The authors hypothesised that the decision to dodge requires considerable sensory integration and planning-robber's location and approach, the size of the food, and the eating time. Thus, if the type 2 theta underlies the selection of an upcoming motor response, this rhythm should occur prior to the dodge initiation and infusion of atropine, a cholinergic antagonist, should disturb the dodging behaviour. Motor abnormalitiesa "collapsed" eating posture and the inability to hold the food between the forelimbs-was reported in the first 5-10 min after atropine application. Prior to the animals' dodging, the frequency of the recorded theta rhythm increased, while the infusion of atropine in the victim's MSDB completely abolished theta activity during the robber's s attempts to steal the food and affected its success in protecting it. Interestingly, once the robber had stolen the food from the victim, the victim was capable to engage as a robber in an attempt to retrieve his food back. The authors conclude that, as the effect seems to be specific to dodging, it is rather not motivational. However, if the motor planning was affected in general, it is not intuitive to expect that the victims would take the role of a robber without displaying locomotion impairments. In our opinion, type 2 theta, and thus the cholinergic system of MSDB relate to locomotion planning only of specific valence, allowing the victim to act once the robber steals its food, but not to protect it from the theft. In this view, it seems that atropine reduce the victim's capability to predict the robber's action, but did not impair its ability to act after the robbery occurred. Thus, it appears that this system is not linked with locomotion in general but with the specific motivation of an animal to move.

Furthermore, if type 2 theta codes the future movement planning, one would expect its presence also during locomotion, not solely during immobility. While Brian Bland has been postulating for years that type 1 and type 2 theta appear coincidentally (Bland and Oddie, 2001), the experimental evidence for it was lacking for a considerable amount of time. One recent study (Mikulovic et al., 2018) has shown that type 2 theta can originate in the ventral HPC. Indeed, ventral HPC receives strong cholinergic input from MSDB and is involved in emotional information processing, in contrast to its dorsal counterpart, known for its role in navigation and cognition (Strange et al., 2014). When animals are taking risks in an anxiety predator-odour test, type 2 theta co-exists with type 1-theta in the ventral HPC. These results additionally support our views that type 2 theta code for locomotion of specific valence. Several other studies support this hypothesis. In an early study (Whishaw and Vanderwolf, 1973), the authors have shown that in a jump avoidance test, where a rat learns to jump to avoid an electrical shock, the recorded theta activity, supposed to correspond to the type 2 theta rhythm, predicts the height of the jump. This study was replicated by Bland et al. (2006) while another study (Balleine and Curthoys, 1991) (discussed in Bland et al., 2007) added an interesting twist to this paradigm. They investigated three different conditions: escapable shock, non-escapable shock and no shock. The rats were trained to each of the condition on the first day and $24 \mathrm{~h}$ later tested, while the oscillatory activity was recorded prior to the shock. Interestingly, while escapable and no shock rats generated theta oscillations during immobility, LIA was recorded in the HPC of the inescapable rats. All this indicates that theta rhythm and the underlying MSDB circuit function as a readout for different movements and internal state of the subject. This information is subsequently transferred to the specific region that receives MSDB inputs, leading to a specific motivation to move (Figure 2). One brain region that is anatomically and functionally close and thus acts in synergy with MSDB is the LS.

\section{SYNERGY BETWEEN MSDB AND LS}

As discussed above, for a long time the septal area was studied as a whole, without paying attention to the different roles played by its medial and lateral part. Over the years, several evidences pointed to the separate, but synergistic effects mediated by these two brain regions. The MSDB, placed in the middle of the basal forebrain, receives inputs from other subcortical nuclei involved in oscillatory activity such as the SUM, LH, NI, and Raphe 


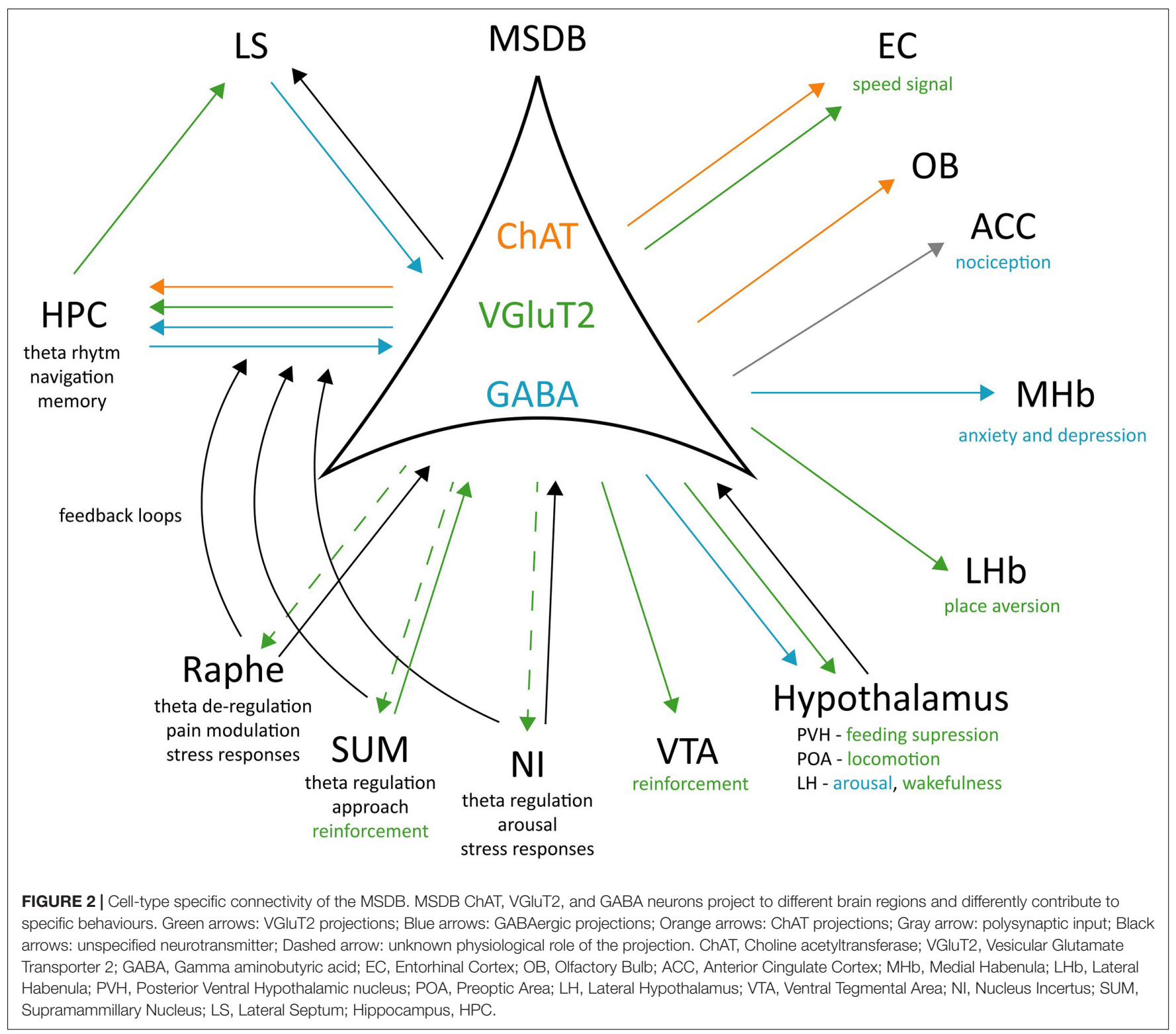

nucleus (Raisman, 1966; Swanson and Cowan, 1979; Ang et al., 2017). They modulate MSDB activity and play a role in the generation or suppression of theta oscillations in the HPC. The LS is also displaying neuronal firing coupled to the theta rhythm (Korotkova et al., 2018). While the MSDB is the major input source to the HPC, LS is one of its most relevant subcortical outputs. Speed-dependent activity has been related to all of these areas with a major difference: MSDB possess pacemaker cells that drive HPC theta even prior to movement initiation (Fuhrmann et al., 2015), while LS theta-locked firing depends on HPC activity (Bender et al., 2015), raising the possibility of a tripartite circuit. In this view, MSDB activation drives HPC oscillations that, in turn, sends the information to the LS about the ongoing motor activity. A recent review on the LS places this structure as a nexus for mood, motivation and movement, postulating its key role in evaluating changes in valence as the result of an animal action (Wirtshafter and Wilson, 2021). This will allow the animal to update its decision whether to act or not depending on the external, context-dependent inputs coming from the HPC and on its internal motivation computed in the LS, based on information flowing from the VTA and other limbic structures. However, also the MSDB has been described as a key element responsible for movement related activity [as MSDB VGluT2 ${ }^{+}$ neurons are sufficient to initiate locomotion (Fuhrmann et al., 2015)], motivation [given the increase in self-stimulation of the animals when activating the MSDB (Cazala et al., 1998; GavelloBaudy et al., 2008)], and mood [see the anxiolytic and anxiogenic effects described after MSDB manipulation (Adhikari et al., 2011; Jiang et al., 2018; Mikulovic et al., 2018)]. It is not surprising that these two regions, given the close anatomical connection and the similar physiological role, also share common effects. The major difference can be found in their connectivity and 
their cell population. The MSDB intensively projects to the HPC driving theta and sending speed-related information to the whole HPC formation [and possibly sending collaterals to the LS too (Tsanov, 2018)]. It is also highly connected with key structures involved in the animal's survival (hypothalamic, midbrain, and brainstem regions) and, given its position on the path of the medial forebrain bundle, is closely linked to locomotion (Sinnamon et al., 1984). Moreover, MSDB contains excitatory and modulatory cell types (ChAT and VGluT2) while the LS is mostly comprised of GABAergic interneurons. Undoubtedly, LS has historically been more connected to mood, being involved in the so called septal rage and given the dense projections to the VTA and other areas linked to reward and motivation. Taken together, these observations allow to speculate about a highly interconnected circuit linking MSDB, HPC, and LS involved in movement, speed regulation, and motivation. However, to fully understand this circuit, future studies should explore the directions of the interconnectivity between MSDB and LS, as well as its physiological role.

\section{FUTURE DIRECTIONS AND OPEN QUESTIONS}

We here reviewed the work that has been done so far to disentangle the role of the MSDB cell populations and their projections in relation to locomotion. The rather recent discovery of the VGluT2 ${ }^{+}$population in the MSDB and the yet little work that has been conducted in studying MSDB inputs outside the HPC formation, opens up a large number of questions. What is the role of the GABAergic projections outside the septum? How do VGluT2 ${ }^{+}$neurons drive locomotion? What is the intra-septal connectivity and how do the different population interact with each other? Do more specific cell-types exist among the previously genetically-defined MSDB neurons? What is the relationship between MSDB and LS during behaviour? And what is the physiological role of the MSDB during locomotion in light of the recent findings?

To answer these questions novel tools and techniques have been developed. On one hand, the study of behavioural correlates linked to neural activity is giving previously unimaginable insights. The possibility to look with sub-second resolution at communities and transitions between different behavioral states allows to correlate single cell firing and oscillations to the animals' action with an unprecedented time resolution (Hong et al., 2015; Wei and Kording, 2018; Luxem et al., 2020; Dunn et al., 2021; Hausmann et al., 2021). Moreover, unsupervised approaches based on machine learning algorithms to score behaviour are replacing manual scoring, which is intrinsically prone to subjective biases and therefore produces results that are hard to compare between studies. On the other hand, development of new genetic tools like faster calcium indicators [jGCaMP8 (Zhang et al., 2020)], more specific opsins to control excitation and inhibition [Opn3 (Mahn et al., 2021), BiPOLES (Vierock et al., 2020)], and novel proteins to detect neuromodulator activity [dLight (Patriarchi et al., 2018), iAChSnFR (Borden et al.,

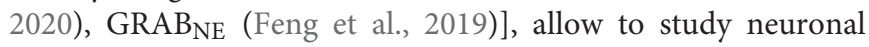

dynamics and manipulate cell-type specific neurons with a higher temporal and spatial resolution. Finally, further developments in technologies like freely moving and wireless miniscopes (Aharoni et al., 2019), GRIN lenses and post hoc recovery of imaged neurons (Xu et al., 2020), are now giving access to studies that were a technological challenge some decades ago.

Employing all these newly available tools to answer the questions above will shed a novel light on the role of MSDB in a behaviour-specific manner.

\section{CONCLUSION}

Medial Septum and diagonal Band of Broca has received substantial attention from the field, mainly due to the fact that its lesion or inhibition leads to the abolishment of theta rhythm in the HPC. While early studies emphasised the role of MSDB in locomotion, this aspect of its function has been somewhat neglected in the last years or solely indirectly studied in relation to the theta rhythm. In this review, we have discussed the role of MSDB circuit manipulation, focussing on locomotion as a behavioural readout. We argue that, although the vast manipulation of MSDB circuits leads to an effect on locomotion-related behaviour, the motivation for this type of movements can be very diverse (Figure 1). For example, cholinergic neurons in MSDB are mainly involved in anxietyrelated locomotion and action valence, GABAergic neurons seem to regulate aversive behaviours, while glutamatergic neurons are the only ones whose activation leads to an immediate motor response. As these three different cell populations project to different brain regions with very diverse functions (Figure 2), we suggest that future studies should rely on novel technologies as well as computational tools to disentangle specific MSDB cell types role in relation to their projection patterns and their behavioural relevance.

\section{AUTHOR CONTRIBUTIONS}

Both authors listed have made a substantial, direct and intellectual contribution to the work, and approved it for publication.

\section{FUNDING}

PM was supported by the German Research Foundation (SFB1089 grant) and the International Max Planck Research School for Brain and Behavior (IMPRS). SM was supported by the Swedish Research Council (International PostDoc grant 2017-06254) and the Leibniz association.

\section{ACKNOWLEDGMENTS}

The authors thank all readers who provided valuable feedback. 


\section{REFERENCES}

Adhikari, A., Topiwala, M. A., and Gordon, J. A. (2010). Synchronized activity between the ventral hippocampus and the medial prefrontal cortex during anxiety. Neuron 65, 257-269. doi: 10.1016/j.neuron.2009.12.002

Adhikari, A., Topiwala, M. A., and Gordon, J. A. (2011). Single units in the medial prefrontal cortex with anxiety-related firing patterns are preferentially influenced by ventral hippocampal activity. Neuron 71, 898-910. doi: 10.1016/j. neuron.2011.07.027

Agostinelli, L. J., Ferrari, L. L., Mahoney, C. E., Mochizuki, T., Lowell, B. B., Arrigoni, E., et al. (2017). Descending projections from the basal forebrain to the orexin neurons in mice. J. Comp. Neurol. 525, 1668-1684. doi: 10.1002/cne. 24158

Aharoni, D., Khakh, B. S., Silva, A. J., and Golshani, P. (2019). All the light that we can see: a new era in miniaturized microscopy. Nat. Methods 16, 11-13. doi: 10.1038/s41592-018-0266- $\mathrm{x}$

Albert, D. J., and Chew, G. L. (1980). The septal forebrain and the inhibitory modulation of attack and defense in the rat. A review. Behav. Neural Biol. 30, 357-388. doi: 10.1016/S0163-1047(80)91247-9

Albert, D. J., and Richmond, S. E. (1975). Septal hyperreactivity: a comparison of lesions within and adjacent to the septum. Physiol. Behav. 15, 339-347. doi: 10.1016/0031-9384(75)90102-X

Altman, J. L., and Wishart, T. B. (1971). Motivated feeding behavior elicited by electrical stimulation of the septum. Physiol. Behav. 6, 105-109. doi: 10.1016/ 0031-9384(71)90076-X

Andersen, P., Bland, H. B., Myhrer, T., and Schwartzkroin, P. A. (1979). Septohippocampal pathway necessary for dentate theta production. Brain Res. 165, 13-22. doi: 10.1016/0006-8993(79)90040-4

Ang, S. T., Ariffin, M. Z., and Khanna, S. (2017). The forebrain medial septal region and nociception. Neurobiol. Learn. Mem. 138, 238-251. doi: 10.1016/j. nlm.2016.07.017

Ang, S. T., Lee, A. T. H., Foo, F. C., Ng, L., Low, C. M., and Khanna, S. (2015). GABAergic neurons of the medial septum play a nodal role in facilitation of nociception-induced affect. Sci. Rep. 5, 1-21. doi: 10.1038/srep15419

Balleine, B. W., and Curthoys, I. S. (1991). Differential effects of escapable and inescapable footshock on hippocampal theta activity. Behav. Neurosci. 105, 202-209. doi: 10.1037/0735-7044.105.1.202

Barbano, M. F., Wang, H. L., Zhang, S., Miranda-Barrientos, J., Estrin, D. J., Figueroa-González, A., et al. (2020). VTA glutamatergic neurons mediate innate defensive behaviors. Neuron 107, 368.e8-382.e8. doi: 10.1016/j.neuron.2020.04. 024

Bender, F., Gorbati, M., Cadavieco, M. C., Denisova, N., Gao, X., Holman, C., et al. (2015). Theta oscillations regulate the speed of locomotion via a hippocampus to lateral septum pathway. Nat. Commun. 6:8521. doi: 10.1038/ncomms9521

Bland, B. H. (1986). The physiology and pharmacology of hippocampal formation theta rhythms. Prog. Neurobiol. 26, 1-54. doi: 10.1016/0301-0082(86)90019-5

Bland, B. H., Derie-Gillespie, D., Mestek, P., Jackson, J., Crooks, R., and Cormican, A. (2007). To move or not: previous experience in a runway avoidance task determines the appearance of hippocampal Type 2 sensory processing theta. Behav. Brain Res. 179, 299-304. doi: 10.1016/j.bbr.2007.02.002

Bland, B. H., Jackson, J., Derrie-Gillespie, D., Azad, T., Rickhi, A., and Abriam, J. (2006). Amplitude, frequency, and phase analysis of hippocampal theta during sensorimotor processing in a jump avoidance task. Hippocampus 16, 673-681. doi: $10.1002 /$ hipo. 20210

Bland, B. H., and Oddie, S. D. (2001). Theta band oscillation and synchrony in the hippocampal formation and associated structures: the case for its role in sensorimotor integration. Behav. Brain Res. 127, 119-136. doi: 10.1016/S01664328(01)00358-8

Bland, B. H., Seto, M. G., Sinclair, B. R., and Fraser, S. M. (1984). The pharmacology of hippocampal theta cells: evidence that the sensory processing correlate is cholinergic. Brain Res. 299, 121-131. doi: 10.1016/0006-8993(84)90794-7

Bland, B. H., and Vanderwolf, C. H. (1972). Electrical stimulation of the hippocampal formation: behavioral and bioelectrical effects. Brain Res. 43, 89-106. doi: 10.1016/0006-8993(72)90276-4

Bonthuis, P. J., Cox, K. H., Searcy, B. T., Kumar, P., Tobet, S., and Rissman, E. F. (2010). Of mice and rats: key species variations in the sexual differentiation of brain and behavior. Front. Neuroendocrinol. 31:341-358. doi: 10.1016/j.yfrne. 2010.05.001
Borden, P. M., Zhang, P., Shivange, A. V., Marvin, J. S., Cichon, J., Dan, C., et al. (2020). A fast genetically encoded fluorescent sensor for faithful in vivo acetylcholine detection in mice, fish, worms and flies. bioRxiv [Preprint]. doi: 10.1101/2020.02.07.939504

Boyce, R., Glasgow, S. D., Williams, S., and Adamantidis, A. (2016). Sleep research: causal evidence for the role of REM sleep theta rhythm in contextual memory consolidation. Science 352, 812-816. doi: 10.1126/science.aad5252

Brady, J. V., and Nauta, W. J. H. (1953). Subcortical mechanisms in emotional behavior: affective changes following septal forebrain lesions in the albino rat. J. Comp. Physiol. Psychol. 46, 339-346. doi: 10.1037/h0059531

Brady, J. V., and Nauta, W. J. H. (1955). Subcortical mechanisms in emotional behavior: the duration of affective changes following septal and habenular lesions in the albino rat. J. Comp. Physiol. Psychol. 48, 412-420. doi: 10.1037/ h0046406

Brandon, M. P., Bogaard, A. R., Libby, C. P., Connerney, M. A., Gupta, K., and Hasselmo, M. E. (2011). Reduction of theta rhythm dissociates grid cell spatial periodicity from directional tuning. Science 332, 595-599. doi: 10.1126/science. 1201652

Brown, T. G. (1914). On the nature of the fundamental activity of the nervous centres; together with an analysis of the conditioning of rhythmic activity in progression, and a theory of the evolution of function in the nervous system. J. Physiol. 48, 18-46. doi: 10.1113/jphysiol.1914.sp001646

Buddington, R. W., King, F. A., and Roberts, L. (1967). Emotionality and conditioned avoidance responding in the squirrel monkey following septal injury. Psychon. Sci. 8, 195-196. doi: 10.3758/BF03331616

Buzsáki, G., Czopf, J., Kondákor, I., and Kellényi, L. (1986). Laminar distribution of hippocampal rhythmic slow activity (RSA) in the behaving rat: current-source density analysis, effects of urethane and atropine. Brain Res. 365, 125-137. doi: 10.1016/0006-8993(86)90729-8

Caggiano, V., Leiras, R., Goñi-Erro, H., Masini, D., Bellardita, C., Bouvier, J., et al. (2018). Midbrain circuits that set locomotor speed and gait selection. Nature 553, 455-460. doi: 10.1038/nature25448

Capelli, P., Pivetta, C., Esposito, M. S., and Arber, S. (2017). Locomotor speed control circuits in the caudal brainstem. Nature 551, 373-377. doi: 10.1038/ nature24064

Caplan, M. (1973). An analysis of the effects of septal lesions on negatively reinforced behavior. Behav. Biol. 9, 129-167. doi: 10.1016/S0091-6773(73) 80153-1

Carpenter, F., Burgess, N., and Barry, C. (2017). Modulating medial septal cholinergic activity reduces medial entorhinal theta frequency without affecting speed or grid coding. Sci. Rep. 7, 1-12. doi: 10.1038/s41598-017-151 00-6

Cazala, P., Galey, D., and Durkin, T. (1988). Electrical self-stimulation in the medial and lateral septum as compared to the lateral hypothalamus: differential intervention of reward and learning processes? Physiol. Behav. 44, 53-59. doi: 10.1016/0031-9384(88)90345-9

Cazala, P., Norena, A., Le Merrer, J., and Galey, D. (1998). Differential involvement of the lateral and medial divisions of the septal area on spatial learning processes as revealed by intracranial self- administration of morphine in mice. Behav. Brain Res. 97, 179-188. doi: 10.1016/S0166-4328(98)00040-0

Choi, K., Lee, Y., Lee, C., Hong, S., Lee, S., Kang, S. J., et al. (2016). Optogenetic activation of septal GABAergic afferents entrains neuronal firing in the medial habenula. Sci. Rep. 6, 1-10. doi: 10.1038/srep34800

Chrobak, J. J., Stackman, R. W., and Walsh, T. J. (1989). Intraseptal administration of muscimol produces dose-dependent memory impairments in the rat. Behav. Neural Biol. 52, 357-369. doi: 10.1016/S0163-1047(89)90472-X

Colom, L. V., Castaneda, M. T., Reyna, T., Hernandez, S., and Garrido-Sanabria, E. (2005). Characterization of medial septal glutamatergic neurons and their projection to the hippocampus. Synapse 58, 151-164. doi: 10.1002/syn.20184

Cui, G., Jun, S. B., Jin, X., Pham, M. D., Vogel, S. S., Lovinger, D. M., et al. (2013). Concurrent activation of striatal direct and indirect pathways during action initiation. Nature 494, 238-242. doi: 10.1038/nature11846

Decker, M. W., Radek, R. J., Majchrzak, M. J., and Anderson, D. J. (1992). Differential effects of medial septal lesions on spatial-memory tasks. Psychobiology 20, 9-17. doi: 10.3758/BF03327154

Decker, M. W., Curzon, P., and Brioni, J. D. (1995). Influence of separate and combined septal and amygdala lesions on memory, acoustic startle, anxiety, and locomotor activity in rats Neurobiol. Learn. Mem. 64, 156-168. 
Donovick, P. J. (1968). Effects of localized septal lesions on hippocampal EEG activity and behavior in rats. J. Comp. Physiol. Psychol. 66, 569-578. doi: 10. 1037/h0026514

Douglas, J., Noga, B., Dai, X., and Jordan, L. (1993). The effects of intrathecal administration of excitatory amino acid agonists and antagonists on the initiation of locomotion in the adult cat. J. Neurosci. 13, 990-1000.

Dunn, T. W., Marshall, J. D., Severson, K. S., Aldarondo, D. E., Hildebrand, D. G. C., Chettih, S. N., et al. (2021). Geometric deep learning enables 3D kinematic profiling across species and environments. Nat. Methods 18, 564-573. doi: 10.1038/s41592-021-01106-6

Dwyer, T. A., Servatius, R. J., and Pang, K. C. H. (2007). Noncholinergic lesions of the medial septum impair sequential learning of different spatial locations. J. Neurosci. 27, 299-303. doi: 10.1523/JNEUROSCI.4189-06.2007

Espinosa, N., Alonso, A., Lara-Vasquez, A., and Fuentealba, P. (2019). Basal forebrain somatostatin cells differentially regulate local gamma oscillations and functionally segregate motor and cognitive circuits. Sci. Rep. 9, 1-12. doi: 10. 1038/s41598-019-39203-4

Feng, J., Zhang, C., Lischinsky, J. E., Jing, M., Zhou, J., Wang, H., et al. (2019). A genetically encoded fluorescent sensor for rapid and specific in vivo detection of norepinephrine. Neuron 102, 745.e8-761.e8. doi: 10.1016/j.neuron.2019.02.037

Ferreira-Pinto, M. J., Ruder, L., Capelli, P., and Arber, S. (2018). Connecting circuits for supraspinal control of locomotion. Neuron 100, 361-374. doi: 10.1016/j. neuron.2018.09.015

Fraser, K. A., Poucet, B., Partlow, G., and Herrmann, T. (1991). Role of the medial and lateral septum in a variable goal spatial problem solving task. Physiol. Behav. 50, 739-744. doi: 10.1016/0031-9384(91)90011-C

Freund, T. F., and Antal, M. (1988). GABA-containing neurons in the septum control inhibitory interneurons in the hippocampus. Nature 336, 170-173. doi: $10.1038 / 336170 \mathrm{a} 0$

Fuhrmann, F., Justus, D., Sosulina, L., Kaneko, H., Beutel, T., Friedrichs, D., et al. (2015). Locomotion, theta oscillations, and the speed-correlated firing of hippocampal neurons are controlled by a medial septal glutamatergic circuit. Neuron 86, 1253-1264. doi: 10.1016/j.neuron.2015.05.001

Gangadharan, G., Shin, J., Kim, S., Kim, A., Paydar, A., and Kim, D. (2016). Medial septal GABAergic projection neurons promote object exploration behavior and type 2 theta rhythm. Proc. Natl. Acad. Sci. U.S.A. 113, 6550-6555. doi: 10.1073/ pnas. 1605019113

Garcia-Rill, E. (1986). The basal ganglia and the locomotor regions. Brain Res. Rev. 11, 47-63. doi: 10.1016/0165-0173(86)90009-3

Gavello-Baudy, S., Le Merrer, J., Decorte, L., David, V., and Cazala, P. (2008). Self-administration of the GABAA agonist muscimol into the medial septum: dependence on dopaminergic mechanisms. Psychopharmacology 201, 219-228. doi: 10.1007/s00213-008-1263-z

Gentil, C. G., Mogenson, G. J., and Stevenson, J. A. (1971). Electrical stimulation of septum, hypothalamus, and amygdala and saline preference. Am. J. Physiol. 220, 1172-1177. doi: 10.1152/ajplegacy.1971.220.5.1172

Gonzalez-Sulser, A., Parthier, D., Candela, A., McClure, C., Pastoll, H., Garden, D., et al. (2014). Gabaergic projections from the medial septum selectively inhibit interneurons in the medial entorhinal cortex. J. Neurosci. 34, 16739-16743. doi: 10.1523/JNEUROSCI.1612-14.2014

Gordon, F. J., and Johnson, A. K. (1981). Electrical stimulation of the septal area in the rat: prolonged suppression of water intake and correlation with self-stimulation. Brain Res. 206, 421-430. doi: 10.1016/0006-8993(81)905 42-4

Gorski, R. A. (1984). Critical role for the medial preoptic area in the sexual differentiation of the brain. Prog. Brain Res. 61, 129-146. doi: 10.1016/S00796123(08)64432-5

Gray, J. A. (1971). Medial septal lesions, hippocampal theta rhythm and the control of vibrissal movement in the freely moving rat. Electroencephalogr. Clin. Neurophysiol. 30, 189-197. doi: 10.1016/0013-4694(71)90053-8

Gupta, A. S., Van Der Meer, M. A. A., Touretzky, D. S., and Redish, A. D. (2012). Segmentation of spatial experience by hippocampal theta sequences. Nat. Neurosci. 15, 1032-1039. doi: 10.1038/nn.3138

Haidar, M., Tin, K., Zhang, C., Nategh, M., Covita, J., Wykes, A. D., et al. (2019). Septal GABA and glutamate neurons express RXFP3 mRNA and depletion of septal RXFP3 impaired spatial search strategy and long-term reference memory in adult mice. Front. Neuroanat. 13:30. doi: 10.3389/fnana.2019.00 030
Hajszan, T., Alreja, M., and Leranth, C. (2004). Intrinsic vesicular glutamate transporter 2-immunoreactive input to septohippocampal parvalbumincontaining neurons: novel glutamatergic local circuit cells. Hippocampus 14, 499-509. doi: 10.1002/hipo.10195

Hausmann, S. B., Vargas, A. M., Mathis, A., and Mathis, M. W. (2021). Measuring and modeling the motor system with machine learning. arxiv [Preprint], Available online at: http://arxiv.org/abs/2103.11775.

Highfield, D., Clements, A., Shalev, U., McDonald, R., Featherstone, R., Stewart, J., et al. (2000). Involvement of the medial septum in stress-induced relapse to heroin seeking in rats. Eur. J. Neurosci. 12, 1705-1713. doi: 10.1046/j.1460-9568. 2000.00037.x

Hinman, J. R., Brandon, M. P., Climer, J. R., Chapman, G. W., and Hasselmo, M. E. (2016). Multiple running speed signals in medial entorhinal cortex. Neuron 91, 666-679. doi: 10.1016/j.neuron.2016.06.027

Hinman, J. R., Dannenberg, H., Alexander, A. S., and Hasselmo, M. E. (2018). Neural mechanisms of navigation involving interactions of cortical and subcortical structures. J. Neurophysiol. 119, 2007-2029. doi: 10.1152/jn.00498. 2017

Hinman, J. R., Penley, S. C., Long, L. L., Escabí, M. A., and Chrobak, J. J. (2011). Septotemporal variation in dynamics of theta: speed and habituation. J. Neurophysiol. 105, 2675-2686. doi: 10.1152/jn.00837.2010

Hok, V., Poucet, B., Duvelle, É, Save, É, and Sargolini, F. (2016). Spatial cognition in mice and rats: similarities and differences in brain and behavior. Wiley Interdiscip. Rev. Cogn. Sci. 7, 406-421. doi: 10.1002/wcs.1411

Hong, W., Kennedy, A., Burgos-Artizzu, X. P., Zelikowsky, M., Navonne, S. G., Perona, P., et al. (2015). Automated measurement of mouse social behaviors using depth sensing, video tracking, and machine learning. Proc. Natl. Acad. Sci. U.S.A. 112, E5351-E5360. doi: 10.1073/pnas.1515982112

Hong, W., Kim, D. W., and Anderson, D. J. (2014). Antagonistic control of social versus repetitive self-grooming behaviors by separable amygdala neuronal subsets. Cell 158, 1348-1361. doi: 10.1016/j.cell.2014.07.049

Hooks, M. S., and Kalivas, P. W. (1995). The role of mesoaccumbens-pallidal circuitry in novelty-induced behavioral activation. Neuroscience 64, 587-597. doi: 10.1016/0306-4522(94)00409-X

Howe, M. W., and Dombeck, D. A. (2016). Rapid signalling in distinct dopaminergic axons during locomotion and reward. Nature 535, 505-510. doi: 10.1038 /nature18942

Hull, E. M., and Dominguez, J. M. (2007). Sexual behavior in male rodents. Horm. Behav. 52, 45-55. doi: 10.1016/j.yhbeh.2007.03.030

Jacob, P. Y., Gordillo-Salas, M., Facchini, J., Poucet, B., Save, E., and Sargolini, F. (2017). Medial entorhinal cortex and medial septum contribute to selfmotion-based linear distance estimation. Brain Struct. Funct. 222, 2727-2742. doi: 10.1007/s00429-017-1368-4

Jiang, Y. Y., Zhang, Y., Cui, S., Liu, F. Y., Yi, M., and Wan, Y. (2018). Cholinergic neurons in medial septum maintain anxiety-like behaviors induced by chronic inflammatory pain. Neurosci. Lett. 671, 7-12. doi: 10.1016/j.neulet.2018.01. 041

Jin, J., Cheng, J., Lee, K. W., Amreen, B., McCabe, K. A., Pitcher, C., et al. (2019). Cholinergic neurons of the medial septum are crucial for sensorimotor gating. J. Neurosci. 39, 5234-5242. doi: 10.1523/JNEUROSCI.0950-18.2019

Jordan, L. M., Liu, J., Hedlund, P. B., Akay, T., and Pearson, K. G. (2008). Descending command systems for the initiation of locomotion in mammals. Brain Res. Rev. 57, 183-191. doi: 10.1016/j.brainresrev.2007.07.019

Jung, H., Kim, S. W., Kim, M., Hong, J., Yu, D., Kim, J. H., et al. (2019). Noninvasive optical activation of Flp recombinase for genetic manipulation in deep mouse brain regions. Nat. Commun. 10:314. doi: 10.1038/s41467-018-08282-8

Justus, D., Dalügge, D., Bothe, S., Fuhrmann, F., Hannes, C., Kaneko, H., et al. (2017). Glutamatergic synaptic integration of locomotion speed via septoentorhinal projections. Nat. Neurosci 20, 16-19. doi: 10.1038/nn.4447

Kesner, A., Shin, R., Calva, C., Don, R., Junn, S., Potter, C., et al. (2020). Supramammillary neurons projecting to the septum regulate dopamine and motivation for environmental interaction. bioRxiv [Preprint]. doi: 10.1101/ 2020.05.15.097857

Khakpai, F., Zarrindast, M. R., Nasehi, M., Haeri-Rohani, A., and Eidi, A. (2013). The role of glutamatergic pathway between septum and hippocampus in the memory formation. EXCLI J. 12, 41-51. doi: 10.17877/DE290R-5594

Kiehn, O. (2016). Decoding the organization of spinal circuits that control locomotion. Nat. Rev. Neurosci. 17, 224-238. doi: 10.1038/nrn.2016.9 
King, F. A. (1958). Effects of septal and amygdaloid lesions on emotional behavior and conditioned avoidance responses in the rat. J. Nerv. Ment. Dis. 126, 57-63. doi: 10.1097/00005053-195801000-00006

Klampfl, S. M., Brunton, P. J., Bayerl, D. S., and Bosch, O. J. (2016). CRF-R1 activation in the anterior-dorsal BNST induces maternal neglect in lactating rats via an HPA axis-independent central mechanism. Psychoneuroendocrinology 64, 89-98. doi: 10.1016/j.psyneuen.2015.11.015

Knox, D., and Keller, S. M. (2016). Cholinergic neuronal lesions in the medial septum and vertical limb of the diagonal bands of Broca induce contextual fear memory generalization and impair acquisition of fear extinction. Hippocampus 26, 718-726. doi: 10.1002/hipo.22553

Kocsis, B., Bragin, A., and Buzsáki, G. (1999). Interdependence of multiple theta generators in the hippocampus: a partial coherence analysis. J. Neurosci. 19, 6200-6212. doi: 10.1523/jneurosci.19-14-06200.1999

Kocsis, B., Martínez-Bellver, S., Fiáth, R., Domonkos, A., Sviatkó, K., Barthó, P., et al. (2021). Huygens synchronization of medial septal pacemaker neurons generates hippocampal theta oscillation. bioRxiv [Preprint]. doi: 10.2139/ssrn. 3773612

Koenig, J., Linder, A. N., Leutgeb, J. K., and Leutgeb, S. (2011). The spatial periodicity of grid cells is not sustained during reduced theta oscillations. Science 332, 592-595. doi: 10.1126/science.1201685

Korotkova, T., Ponomarenko, A., Monaghan, C. K., Poulter, S. L., Cacucci, F., Wills, T., et al. (2018). Reconciling the different faces of hippocampal theta: the role of theta oscillations in cognitive, emotional and innate behaviors. Neurosci. Biobehav. Rev. 85, 65-80. doi: 10.1016/j.neubiorev.2017.09.004

Korvasová, K., Ludwig, F., Kaneko, H., Sosulina, L., Remy, S., Tetzlaff, T., et al. (2021). Locomotion induced by the medial septal glutamatergic neurons is linked to persistent activity. bioRxiv [Preprint]. doi: 10.1101/2021.04.23.441 122

Kramis, R., Vanderwolf, C. H., and Bland, B. H. (1975). Two types of hippocampal rhythmical slow activity in both the rabbit and the rat: relations to behavior and effects of atropine, diethyl ether, urethane, and pentobarbital. Exp. Neurol. 49, 58-85. doi: 10.1016/0014-4886(75)90195-8

Kramis, R. C., and Routtenberg, A. (1977). Dissociation of hippocampal EEG from its behavioral correlates by septal and hippocampal electrical stimulation. Brain Res. 125, 37-49. doi: 10.1016/0006-8993(77)90358-4

Krashes, M. J., Koda, S., Ye, C. P., Rogan, S. C., Adams, A. C., Cusher, D. S., et al. (2011). Rapid, reversible activation of AgRP neurons drives feeding behavior in mice. J. Clin. Invest. 121, 1424-1428. doi: 10.1172/JCI46229

Kropff, E., Carmichael, J. E., Moser, E. I., and Moser, M.-B. (2021). Frequency of theta rhythm is controlled by acceleration, but not speed, in running rats. Neuron 109, 1029.e8-1039.e8. doi: 10.1016/j.neuron.2021.01.017

Kuroda, K. O., and Numan, M. (2014). The medial preoptic area and the regulation of parental behavior. Neurosci. Bull. 30, 863-865. doi: 10.1007/s12264-0141462-z

Lamprea, M. R., Garcia, A. M. B., and Morato, S. (2010). Effects of reversible inactivation of the medial septum on rat exploratory behavior in the elevated plus-maze using a test-retest paradigm. Behav. Brain Res. 210, 67-73. doi: 10. 1016/j.bbr.2010.02.011

Lee, E. H. Y., Lin, Y. P., and Yin, T. H. (1988). Effects of lateral and medial septal lesions on various activity and reactivity measures in rats. Physiol. Behav. 42, 97-102. doi: 10.1016/0031-9384(88)90267-3

Lee, M. G., Chrobak, J. J., Sik, A., Wiley, R. G., and Buzsáki, G. (1994). Hippocampal theta activity following selective lesion of the septal cholinergic systeM. Neuroscience 62, 1033-1047. doi: 10.1016/0306-4522(94)90341-7

Li, N., Chen, T. W., Guo, Z. V., Gerfen, C. R., and Svoboda, K. (2015). A motor cortex circuit for motor planning and movement. Nature 519, 51-56. doi: 10. 1038/nature 14178

Lin, D., Boyle, M. P., Dollar, P., Lee, H., Lein, E. S., Perona, P., et al. (2011). Functional identification of an aggression locus in the mouse hypothalamus. Nature 470, 221-227. doi: 10.1038/nature09736

Lubar, J. F. (1964). Effect of medial cortical lesions on the avoidance behavior of the cat. J. Comp. Physiol. Psychol. 58, 38-46. doi: 10.1037/h0041014

Luxem, K., Fuhrmann, F., Kursch, J., Remy, S., and Bauer, P. (2020). Identifying behavioral structure from deep variational embeddings of animal motion. bioRxiv [Preprint]. doi: 10.1101/2020.05.14.095430

Ma, J., and Leung, L. S. (2007). The supramammillo - septal - hippocampal pathway mediates sensorimotor gating impairment and hyperlocomotion induced by MK-801 and ketamine in rats. Psychopharmacology 191, 961-974. doi: 10.1007/s00213-006-0667-x

Mabry, P. D., and Peeler, D. F. (1968). Response rate for food and water in the rat as a function of noncontingent, reinforcing septal stimulation. Psychon. Sci. 13, 51-52. doi: 10.3758/bf03342404

Mahn, M., Saraf-Sinik, I., Patil, P., Pulin, M., Bitton, E., Karalis, N., et al. (2021). Optogenetic silencing of neurotransmitter release with a naturally occurring invertebrate rhodopsin. bioRxiv [Preprint]. doi: 10.1101/2021.02.18.431673

Mamad, O., McNamara, H. M., Reilly, R. B., and Tsanov, M. (2015). Medial septum regulates the hippocampal spatial representation. Front. Behav. Neurosci. 9:166. doi: 10.3389/fnbeh.2015.00166

Manns, I. D., Mainville, L., and Jones, B. E. (2001). Evidence for glutamate, in addition to acetylcholine and GABA, neurotransmitter synthesis in basal forebrain neurons projecting to the entorhinal cortex. Neuroscience 107, 249263. doi: $10.1016 / \mathrm{S} 0306-4522(01) 00302-5$

Manseau, F., Danik, M., and Williams, S. (2005). A functional glutamatergic neurone network in the medial septum and diagonal band area. J. Physiol. 566, 865-884. doi: 10.1113/jphysiol.2005.089664

Martin, J. H., and Ghez, C. (1999). Pharmacological inactivation in the analysis of the central control of movement. J. Neurosci. Methods 86, 145-159. doi: 10.1016/S0165-0270(98)00163-0

McCleary, R. A., Jones, C., and Ursine, H. (1965). Avoidance and retention deficits in septal cats. Psychon. Sci. 2, 85-86. doi: 10.3758/bf03343342

Meibach, R. C., and Siegel, A. (1977). Efferent connections of the septal area in the rat: an analysis utilizing retrograde and anterograde transport methods. Brain Res. 119, 1-20. doi: 10.1016/0006-8993(77)90088-9

Mikulovic, S., Restrepo, C. E., Siwani, S., Bauer, P., Pupe, S., Tort, A. B. L., et al. (2018). Ventral hippocampal OLM cells control type 2 theta oscillations and response to predator odor. Nat. Commun 9:3638. doi: 10.1038/s41467-01805907-w

Mogenson, G. J., Jones, D. L., and Yim, C. Y. (1980). From motivation to action: functional interface between the limbic system and the motor system. Prog. Neurobiol. 14, 69-97. doi: 10.1016/0301-0082(80)90018-0

Mogenson, G. J., Wu, M., and Machanda, S. K. (1979). Locomotor activity initiated by microinfusions of picrotoxin into the ventral tegmental area. Brain Res. 161, 311-319. doi: 10.1016/0006-8993(79)90072-6

Molas, S., Zhao-Shea, R., Liu, L., Degroot, S. R., Gardner, P. D., and Tapper, A. R. (2017). A circuit-based mechanism underlying familiarity signaling and the preference for novelty. Nat. Neurosci. 20, 1260-1268. doi: 10.1038/nn.4607

Müller, C., and Remy, S. (2018). Septo-hippocampal interaction. Cell Tissue Res. 373, 565-575. doi: 10.1007/s00441-017-2745-2

Myhrer, T. (1989). Exploratory behavior and reaction to novelty in rats: effects of medial and lateral septal lesions. Behav. Neurosci. 103, 99-106.

Nagahara, A. H., and McGaugh, J. L. (1992). Muscimol infused into the medial septal area impairs long-term memory but not short-term memory in inhibitory avoidance, water maze place learning and rewarded alternation tasks. Brain Res. 591, 54-61. doi: 10.1016/0006-8993(92)90977-H

Ng, S. Y., Lee, A. T. H., Ariffin, M. Z., Woon, P. J., Chng, T. S. H., and Khanna, S. (2020). Medial septum neurokinin- and somatostatin-sensitive mechanisms mediate sensorimotor and nociceptive behaviours. bioRxiv [Preprint]. doi: 10. $1101 / 2020.10 .27 .358267$

Noonan, M., and Kristal, M. B. (1979). Effects of medial preoptic lesions on placentophagia and on the onset of maternal behavior in the rat. Physiol. Behav. 22, 1197-1202. doi: 10.1016/0031-9384(79)90276-2

Oddie, S. D., Kirk, I. J., Whishaw, I. Q., and Bland, B. H. (1997). Hippocampal formation is involved in movement selection: evidence from medial septal cholinergic modulation and concurrent slow-wave (theta rhythm) recording. Behav. Brain Res. 88, 169-180. doi: 10.1016/S0166-4328(97)022 90-0

Okada, K., and Okaichi, H. (2010). Functional cooperation between the hippocampal subregions and the medial septum in unreinforced and reinforced spatial memory tasks. Behav. Brain Res. 209, 295-304. doi: 10.1016/j.bbr.2010. 02.007

Olds, J., and Milner, P. (1954). Positive reinforcement produced by electrical stimulation of septal area and other regions of rat brain. J. Comp. Physiol. Psychol. 47, 419-427. doi: 10.1037/h0058775

Osborne, P. G. (1994). A GABAergic mechanism in the medial septum influences cortical arousal and locomotor activity but not a previously learned spatial 
discrimination task. Neurosci. Lett. 173, 63-66. doi: 10.1016/0304-3940(94) 90150-3

Pang, K. C. H., Jiao, X., Sinha, S., Beck, K. D., and Servatius, R. J. (2011). Damage of GABAergic neurons in the medial septum impairs spatial working memory and extinction of active avoidance: effects on proactive interference. Hippocampus 21, 835-846. doi: 10.1002/hipo.20799

Parker, S. M., and Sinnamon, H. M. (1983). Forward locomotion elicited by electrical stimulation in the diencephalon and mesencephalon of the awake rat. Physiol. Behav. 31, 581-587.

Patriarchi, T., Cho, J. R., Merten, K., Howe, M. W., Marley, A., Xiong, W. H., et al. (2018). Ultrafast neuronal imaging of dopamine dynamics with designed genetically encoded sensors. Science 360:eaat 4422 . doi: 10.1126/science.aat 4422

Pepeu, G., and Giovannini, M. G. (2004). Changes in acetylcholine extracellular levels during cognitive processes. Learn. Mem. 11, 21-27. doi: 10.1101/lm. 68104

Petersen, P. C., and Buzsáki, G. (2020). Cooling of medial septum reveals theta phase lag coordination of hippocampal cell assemblies. Neuron 107, 731.e3744.e3. doi: 10.1016/j.neuron.2020.05.023

Petsche, H., and Stumpf, C. (1960). Topographic and toposcopic study of origin and spread of the regular synchronized arousal pattern in the rabbit. Electroencephalogr. Clin. Neurophysiol. 12, 589-600. doi: 10.1016/00134694(60)90101-2

Petsche, H., Stumpf, C., and Gogolak, G. (1962). The significance of the rabbit's septum as a relay station between the midbrain and the hippocampus I. The control of hippocampus arousal activity by the septum cells. Electroencephalogr. Clin. Neurophysiol. 14, 202-211. doi: 10.1016/0013-4694(62)90030-5

Pickenhain, L., and Klingberg, F. (1967). Hippocampal slow wave activity as a correlate of basic behavioral mechanisms in the rat. Prog. Brain Res. 27, 218-227. doi: 10.1016/S0079-6123(08)63101-5

Poplawsky, A., and Johnson, D. A. (1973). Open-field social behavior of rats following lateral or medial septal lesions. Physiol. Behav. 11, 845-854. doi: 10.1016/0031-9384(73)90279-5

Qualls-Creekmore, E., and Münzberg, H. (2018). Modulation of feeding and associated behaviors by lateral hypothalamic circuits. Endocrinology 159, 36313642. doi: 10.1210/en.2018-00449

Qualls-Creekmore, E., Yu, S., Francois, M., Hoang, J., Huesing, C., Bruce-Keller, A., et al. (2017). Galanin-expressing GABA neurons in the lateral hypothalamus modulate food reward and noncompulsive locomotion. J. Neurosci. 37, 60536065. doi: 10.1523/jneurosci.0155-17.2017

Raisman, G. (1966). The connexions of the septum. Brain 89, 317-348. doi: 10. 1093/brain/89.2.317

Robinson, F. R. (1995). Role of the cerebellum in movement control and adaptation. Curr. Opin. Neurobiol. 5, 755-762. doi: 10.1016/0959-4388(95) 80103-0

Robinson, J., Ducharme, G., Vigneault, E., El Mestikawy, S., and Williams, X. S. (2016). Optogenetic activation of septal glutamatergic neurons drive hippocampal theta rhythms. J. Neurosci. 36, 3016-3023. doi: 10.1523/ JNEUROSCI.2141-15.2016

Sainsbury, R. S. (1970). Hippocampal activity during natural behavior in the guinea pig. Physiol. Behav. 5, 317-324. doi: 10.1016/0031-9384(70)90104-6

Sainsbury, R. S., and Montoya, C. P. (1984). The relationship between type 2 theta and behavior. Physiol. Behav. 33, 621-626. doi: 10.1016/0031-9384(84)90381-0

Salib, M., Joshi, A., Katona, L., Howarth, M., Micklem, B. R., Somogyi, P., et al. (2019). GABAergic medial septal neurons with low-rhythmic firing innervating the dentate gyrus and hippocampal area CA3. J. Neurosci. 39, 4527-4549. doi: 10.1523/JNEUROSCI.3024-18.2019

Schlesiger, M. I., Ruff, T., MacLaren, D. A. A., Barriuso-Ortega, I., Saidov, K. M., Yen, T. Y., et al. (2021). Two septal-entorhinal GABAergic projections differentially control coding properties of spatially tuned neurons in the medial entorhinal cortex. Cell Rep. 34:108801. doi: 10.1016/j.celrep.2021.108801

Scott, J. P. (1966). Agonistic behavior of mice and rats: a review. Integr. Comp. Biol. 6, 683-701. doi: 10.1093/icb/6.4.683

Sherrington, C. S. (1910). Flexion-reflex of the limb, crossed extension-reflex, and reflex stepping and standing. J. Physiol. 40, 28-121. doi: 10.1113/jphysiol.1910. sp001362

Sinnamon, H. M. (1992). Microstimulation mapping of the basal forebrain in the anesthetized rat: the "preoptic locomotor region.". Neuroscience 50, 197-207. doi: 10.1016/0306-4522(92)90392-F
Sinnamon, H. M., Ginzburg, R. N., and Kurose, G. A. (1987). Midbrain stimulation in the anesthetized rat: direct locomotor effects and modulation of locomotion produced by hypothalamic stimulation. Neuroscience 20, 695-707. doi: 10.1016/ 0306-4522(87)90120-5

Sinnamon, H. M., Lee, S. H., Adams, D. B., and Stopford, C. K. (1984). Locomotor stepping elicited by electrical stimulation of the lateral hypothalamus requires an ipsilateral descending pathway. Physiol. Behav. 33, 209-215. doi: 10.1016/ 0031-9384(84)90101-X

Sodetz, F. J., Matalka, E. S., and Bunnell, B. N. (1967). Septal ablation and affective behavior in the golden hamster. Psychon. Sci. 7, 189-190. doi: 10.3758/ BF03328532

Sotty, F., Danik, M., Manseau, F., Laplante, F., Quirion, R., and Williams, S. (2003). Distinct electrophysiological properties of glutamatergic, cholinergic and GABAergic rat septohippocampal neurons: novel implications for hippocampal rhythmicity. J. Physiol. 551, 927-943. doi: 10.1113/jphysiol.2003. 046847

Spiegel, E. A., Miller, H. R., and Oppenheimer, M. J. (1940). Forebrain and rage reactions. J. Neurophysiol. 3, 538-548. doi: 10.1152/jn.1940.3.6.538

Strange, B. A., Witter, M. P., Lein, E. S., and Moser, E. I. (2014). Functional organization of the hippocampal longitudinal axis. Nat. Rev. Neurosci. 15, 655-669. doi: 10.1038/nrn3785

Subramanian, S., Reichard, R. A., Stevenson, H. S., Schwartz, Z. M., Parsley, K. P., and Zahm, D. S. (2018). Lateral preoptic and ventral pallidal roles in locomotion and other movements. Brain Struct. Funct. 223, 2907-2924. doi: 10.1007/s00429-018-1669-2

Swanson, L. W., and Cowan, W. M. (1979). The connections of the septal region in the rat. J. Comp. Neurol. 186, 621-655. doi: 10.1002/cne.901860408

Sweeney, P., Li, C., and Yang, Y. (2017). Appetite suppressive role of medial septal glutamatergic neurons. Proc. Natl. Acad. Sci. U.S.A. 114, 13816-13821. doi: $10.1073 /$ pnas. 1707228114

Tang, C., Pawlak, A. P., Prokopenko, V., and West, M. O. (2007). Changes in activity of the striatum during formation of a motor habit. Eur. J. Neurosci. 25, 1212-1227. doi: 10.1111/j.1460-9568.2007.05353.x

Tsanov, M. (2018). Differential and complementary roles of medial and lateral septum in the orchestration of limbic oscillations and signal integration. Eur. J. Neurosci. 48, 2783-2794. doi: 10.1111/ejn.13746

Tye, K. M., Prakash, R., Kim, S. Y., Fenno, L. E., Grosenick, L., Zarabi, H., et al. (2011). Amygdala circuitry mediating reversible and bidirectional control of anxiety. Nature 471, 358-362. doi: 10.1038/nature 09820

Unal, G., Joshi, A., Viney, T. J., Kis, V., and Somogyi, P. (2015). Synaptic targets of medial septal projections in the hippocampus and extrahippocampal cortices of the mouse. J. Neurosci. 35, 15812-15826. doi: 10.1523/JNEUROSCI.2639-15. 2015

Vaidya, A. R., Pujara, M. S., Petrides, M., Murray, E. A., and Fellows, L. K. (2019). Lesion studies in contemporary neuroscience. Trends Cogn. Sci. 23, 653-671. doi: 10.1016/j.tics.2019.05.009

Vanderwolf, C. H. (1968). Hippocampal electrical activity and voluntary movement in the rat. Electroencephalogr. Clin. Neurophysiol 26, 407-418. doi: 10.1053/j. semss.2007.06.005

Varga, V., Hangya, B., Kránitz, K., Ludányi, A., Zemankovics, R., Katona, I., et al. (2008). The presence of pacemaker HCN channels identifies theta rhythmic GABAergic neurons in the medial septum. J. Physiol. 586, 3893-3915. doi: 10.1113/jphysiol.2008.155242

Vickstrom, C. R., Liu, X., Liu, S., Hu, M. M., Mu, L., Hu, Y., et al. (2020). Role of endocannabinoid signaling in a septohabenular pathway in the regulation of anxiety- and depressive-like behavior. Mol. Psychiatry 10.1038/s41380-02000905-1. doi: 10.1038/s41380-020-00905-1 Available Online at: https://www. nature.com/articles/s41380-020-00905-1

Vierock, J., Rodriguez-Rozada, S., Pieper, F., Dieter, A., Bergs, A., Zeitzschel, N., et al. (2020). BiPOLES: a tool for bidirectional dual-color optogenetic control of neurons. bioRxiv [Preprint]. doi: 10.1101/2020.07.15.204347

Votaw, C. L. (1960). Study of septal stimulation and ablation in the macaque monkey. Neurology 10:202. doi: 10.1212/WNL.10.2.202

Walsh, T. J., Gandhi, C., and Stackman, R. W. (1998). Reversible inactivation of the medial septum or nucleus basalis impairs working memory in rats: a dissociation of memory and performance. Behav. Neurosci. 112, 1114-1124. doi: $10.1037 / 0735-7044.112 .5 .1114$ 
Wang, Y., Romani, S., Lustig, B., Leonardo, A., and Pastalkova, E. (2015). Theta sequences are essential for internally generated hippocampal firing fields. Nat. Neurosci. 18, 282-288. doi: 10.1038/nn.3904

Watson, T. C., Obiang, P., Torres-Herraez, A., Watilliaux, A., Coulon, P., Rochefort, C., et al. (2019). Anatomical and physiological foundations of cerebello-hippocampal interaction. eLife 8, 1-28. doi: 10.7554/eLife.41896.001

Wei, K., and Kording, K. P. (2018). Behavioral tracking gets real. Nat. Neurosci. 21, 1146-1147. doi: 10.1038/s41593-018-0215-0

Whishaw, I. Q., and Schallert, T. (1977). Hippocampal RSA (theta), apnea, bradycardia and effects of atropine during underwater swimming in the rat. Electroencephalogr. Clin. Neurophysiol. 42, 389-396. doi: 10.1016/00134694(77)90175-4

Whishaw, I. Q., and Vanderwolf, C. H. (1973). Hippocampal EEG and behavior: change in amplitude and frequency of RSA (Theta rhythm) associated with spontaneous and learned movement patterns in rats and cats. Behav. Biol. 8, 461-484. doi: 10.1016/S0091-6773(73) 80041-0

Winter, S. S., Clark, B. J., and Taube, J. S. (2015). Disruption of the head direction cell network impairs the parahippocampal grid cell signal. Science 347, 870-874. doi: 10.1126/science.1259591

Wirtshafter, H. S., and Wilson, M. A. (2021). Lateral septum as a nexus for mood, motivation, and movement. Neurosci. Biobehav. Rev. 126, 544-559. doi: 10. 1016/j.neubiorev.2021.03.029

Wishart, T. B., Bland, B. H., Vanderwolf, C. H., and Altman, J. L. (1973). Electroencephalographic correlates of behaviors elicited by electrical stimulation of the septum: seizure induced feeding. Behav. Biol. 9, 763-769. doi: 10.1016/S0091-6773(73)80137-3

Wishart, T. B., and Mogenson, G. J. (1970). Reduction of water intake by electrical stimulation of the septal region of the rat brain. Physiol. Behav. 5, 1399-1404. doi: 10.1016/0031-9384(70)90126-5

Wong, L. C., Wang, L., D’Amour, J. A., Yumita, T., Chen, G., Yamaguchi, T., et al. (2016). Effective modulation of male aggression through lateral septum to medial hypothalamus projection. Curr. Biol. 26, 593-604. doi: 10.1016/j.cub. 2015.12.065

Wu, M., Zhang, Z., Leranth, C., Xu, C., Van den Pol, A. N., and Alreja, M. (2002). Hypocretin increases impulse flow in the septohippocampal GABAergic pathway: implications for arousal via a mechanism of hippocampal disinhibition. J. Neurosci. 22, 7754-7765. doi: 10.1523/jneurosci.22-17-07754. 2002

Xu, S., Yang, H., Menon, V., Lemire, A. L., Wang, L., Henry, F. E., et al. (2020). Behavioral state coding by molecularly defined paraventricular hypothalamic cell type ensembles. Science 370:eabb2494. doi: 10.1126/science.abb2494

Yoshii, N., Shimokochi, M., Miyamoto, K., and Ito, M. (1966). Studies on the neural basis of behavior by continuous frequency analysis of EEG. Prog. Brain Res. 21, 217-250. doi: 10.1016/S0079-6123(08)62979-9

Zarrindast, M. R., Moghimi, M., Rostami, P., and Rezayof, A. (2006). Histaminergic receptors of medial septum and conditioned place preference: D1 dopamine receptor mechanism. Brain Res. 1109, 108-116. doi: 10.1016/j.brainres.2006.06. 024

Zhang, G. W., Shen, L., Zhong, W., Xiong, Y., Zhang, L. I., and Tao, H. W. (2018). Transforming sensory cues into aversive emotion via septal-habenular pathway. Neuron 99, 1016.e5-1028.e5. doi: 10.1016/j.neuron.2018.07.023

Zhang, Y., Jiang, Y. Y., Shao, S., Zhang, C., Liu, F. Y., Wan, Y., et al. (2017) Inhibiting medial septal cholinergic neurons with DREADD alleviated anxietylike behaviors in mice. Neurosci. Lett. 638, 139-144. doi: 10.1016/j.neulet.2016. 12.010

Zhang, Y., Rózsa, M., Bushey, D., Zheng, J., Reep, D., Liang, Y., et al. (2020). jGCaMP8: ultra-sensitive protein calcium sensors with fast kinetics. Available Online at: https://www.janelia.org/jgcamp8-calcium-indicators\#citing

Zutshi, I., Brandon, M. P., Fu, M. L., Donegan, M. L., Leutgeb, J. K., and Leutgeb, S. (2018). Hippocampal neural circuits respond to optogenetic pacing of theta frequencies by generating accelerated oscillation frequencies. Curr. Biol. 28, 1179.e3-1188.e3. doi: 10.1016/j.cub.2018.02.061

Conflict of Interest: The authors declare that the research was conducted in the absence of any commercial or financial relationships that could be construed as a potential conflict of interest.

Copyright (c) 2021 Mocellin and Mikulovic. This is an open-access article distributed under the terms of the Creative Commons Attribution License (CC BY). The use, distribution or reproduction in other forums is permitted, provided the original author(s) and the copyright owner(s) are credited and that the original publication in this journal is cited, in accordance with accepted academic practice. No use, distribution or reproduction is permitted which does not comply with these terms. 